\title{
Amorphous silicon PEC-PV hybrid structure for photo-electrochemical water splitting
}

\author{
Miroslav Mikolasek*, Martin Kemeny*, \\ Filip Chymo*, Peter Ondrejka*, Jozef Huran ${ }^{* *}$
}

\begin{abstract}
The paper presents fabrication and characterization of amorphous silicon carbide (a-SiC:H) based structures for photoelectrochemical (PEC) water splitting. The increase of the photocurrent of PEC upon the decreased of $\mathrm{CH}_{4}$ flow during the deposition is associated with the decrease of the band gap and increased absorption of light in a-SiC:H. Photocurrent of $50 \mu \mathrm{A} / \mathrm{cm}^{2}$ is achieved for PEC structure prepared with the lowest $\mathrm{CH}_{4}$ flow during the deposition. An ITO/a-SiC:H/Si silicon heterojunction structure forming a simple photovoltaic cell (PV) with efficiency of $9.66 \%$ was prepared to support additional voltage hereby forming a hybrid PEC-PV system. ASA simulation revealed that a photocurrent of $0.62 \mathrm{~mA} / \mathrm{cm}^{2}$ and solar to hydrogen efficiency of $0.76 \%$ can be achieved for hybrid a PEC-PV structure with 5 PVs connected in series behind the PEC cell. Further opportunities for increasing the performance are discussed and summarized.
\end{abstract}

K e y w or ds: amorphous silicon, photo-electrochemical cell, hydrogen generation, PEC-PV hybrid system

\section{Introduction}

Among the renewable energy sources, solar energy is the only source that has the potential to meet all our energy needs. The most attractive and promising approaches for usage of solar energy are photovoltaic (PV) conversion into electricity [1-3] and photo-electrochemical (PEC) conversion into the chemical fuel (solar fuel) [4-7]. Electricity generation by PV systems is already well established and reaches technological maturity. Production of energy by $\mathrm{PV}$ is limited by the requirement to use energy storage systems for continual energy supply. Such a limitation can be overcome by PEC hydrogen generation, which can address several energy and sustainability challenges by providing a way of storing solar energy to make it available for use when it is needed and by providing fuels which can replace fossil fuels. For a semiconductor material to be used for PEC hydrogen generation the minimum voltage of $1.23 \mathrm{~V}$ is required to split water by two processes that take place simultaneously: (i) hydrogen evolution reaction (HER), and (ii) oxygen evolution reaction (OER). This means that a photovoltage of $1.23 \mathrm{~V}$ or higher has to be provided by PEC structure to perform a self-driven water splitting reaction powered only by solar light. Materials with wide band gaps such as $\mathrm{TiO}_{2}$ can provide a high photovoltage. However, they can absorb only a small part of the solar spectrum [810]. Because of this, these materials provide a low photocurrent and low solar to hydrogen conversion. On the other hand, silicon with a band gap of $1.12 \mathrm{eV}$ can effectively absorb solar light and provide photocurrent up to
$44 \mathrm{~mA} / \mathrm{cm}^{2}$. The small band gap of silicon, however, limits the achieved photovoltage, which is well below $1.23 \mathrm{~V}$ required for water splitting. Currently, there is no material which can provide high a photovoltage and photocurrent simultaneously. As a possible solution for this problem, a hybrid PEC-PV system based on a combination of PEC for hydrogen or oxygen evolution reaction and $\mathrm{PV}$ as a source of additional photovoltage was proposed [10-12]. Amorphous silicon carbide (a-SiC:H) represents one of the most appealing materials for preparation of hybrid PEC-PV structures [13, 14]. The main advantage of this material is possible tuning of the band gap by incorporation of carbon into the film and possible current matching with PV cell. Amorphous silicon carbide is already well established in current PV technologies with well-developed production capacities and can be easily transferred for fabrication of PEC structures.

This paper presents fabrication and characterization of a-SiC:H based PEC and PV structures and simulation of hybrid PEC-PV structure for water splitting. Figure 1 shows interconnection of PEC with 3 silicon heterojunction solar cells (SHJ), which utilizes the transmitted light through PEC and forms a hybrid PEC-PV system. Efficiency analysis of such a hybrid PEC-PV system is provided by utilizing the ASA software. Further directions towards performance improvement of the prepared structures are suggested and analyzed.

\section{Experimental}

The thin film PEC photocathodes were prepared with following layer sequence: Glass-ITO/a-SiC:H(p)_50nm

\footnotetext{
*Institute of Electronics and Photonics, Slovak University of Technology, Ilkovičova 3, 81219 Bratislava, Slovakia, **Institute of Electrical Engineering, Slovak Academy of Sciences, Dúbravská cesta 9, 84104 Bratislava, Slovakia, miroslav.mikolasek@stuba.sk
}

DOI: 10.2478 /jee-2019-0050, Print (till 2015) ISSN 1335-3632, On-line ISSN 1339-309X 


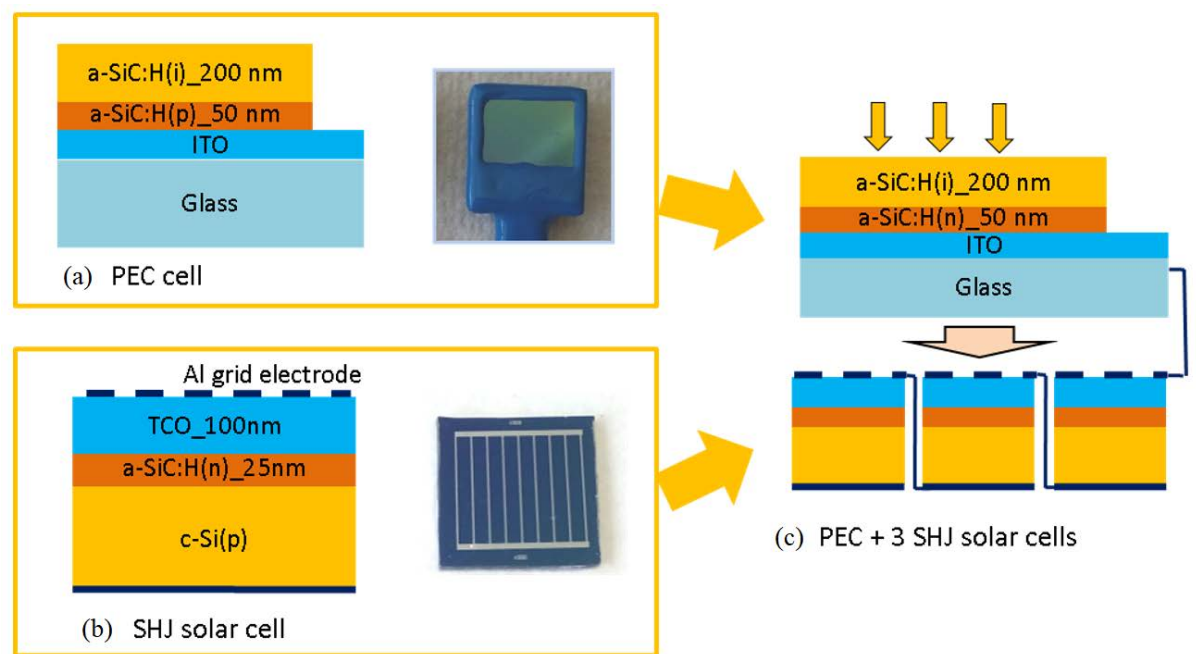

Fig. 1. Schematic drafts of: (a) - photo-electrochemical cell (PEC), (b) - silicon heterojunction solar cell, (c) - hybrid PEC-PV structure formed by a combination of PEC and 3 SHJ solar cells

/a-SiC:H(i)_200 nm, Fig. 1(b). Both a-SiC:H layers were prepared by PECVD on ITO coated glass with these deposition parameters: $\mathrm{SiH}_{4}=5 \mathrm{sccm}, \mathrm{H}_{2}=100 \mathrm{sccm}$, and $\mathrm{Ar}=10 \mathrm{sccm}$. $\mathrm{B}_{2} \mathrm{H}_{6}$ ( 5 vol. $\%$ in $\left.\mathrm{H}_{2}\right)$ with a flow of $6 \mathrm{sccm}$ was used as a dopant of a-SiC:H(p). Three PEC structures were prepared with varied $\mathrm{CH}_{4}$ flows of 10 , 5 and $3 \mathrm{sccm}$ used for both doped and intrinsic a-SiC:H layers, labelled as PEC1, PEC2 and PEC3, respectively.

The silicon heterojunction (SHJ) samples with an area of $1 \mathrm{~cm}^{2}$ and layer sequence a-SiC:H(n)_25nm/c$\mathrm{Si}(\mathrm{p}) \_525 \mu \mathrm{m} / \mathrm{Al}$, Fig. 1(a), were prepared with PECVD deposited a-SiC:H layer $\left(\mathrm{SiH}_{4}=10 \mathrm{sccm}, \mathrm{CH}_{4}=3 \mathrm{sccm}\right.$, $\mathrm{H}_{2}=100$ sccm, $\mathrm{PH}_{3}\left(2\right.$ vol. $\%$ in $\left.\mathrm{H}_{2}\right)=5 \mathrm{sccm}$ and $\mathrm{Ar}=10 \mathrm{sccm})$ on a Si substrate [15]. The substrate temperature was $230^{\circ} \mathrm{C}$, pressure $100 \mathrm{~Pa}$ and high frequency power of $50 \mathrm{~W}$. Before deposition of indium tin oxide (ITO), standard cleaning in a solution of HF was performed to remove native oxide. The targets with composition of $\mathrm{In}_{2} \mathrm{O}_{3}-\mathrm{SnO}_{2}$ and $\mathrm{In}_{2} \mathrm{O}_{3}(90 \%)-\mathrm{ZnO}(10 \%)$ were used for preparation of indium tin oxide with a thickness of $100 \mathrm{~nm}$ by magnetron sputtering. During the deposition the pressure was kept down to $0.6 \mathrm{~Pa}$ and Ar flow was $50 \mathrm{sccm}$. The grid finger electrode of $\mathrm{Al}$ (200 nm thick) and full area $\mathrm{Al}(\sim 250 \mathrm{~nm}$ thick $)$ were prepared as a top and bottom contacts on the samples.

The optical transmittance was evaluated by spectrometer Ocean Optics. Light current-voltage $(I-V)$ measurements were carried out by source-meter Keithley 2612 and solar simulator with AM 1.5 spectrum. Linear sweep voltammetry of PEC structures were provided in a 3 electrode set-up with a $\mathrm{Pt}$ counter electrode and $\mathrm{Ag} / \mathrm{AgCl}$ reference electrode in $\mathrm{H}_{2} \mathrm{SO}_{4}$ electrolyte $(\mathrm{pH}=3)$ by using potentiostat AUTOLAB PGSTAT128N. The sweep rate during the measurement was $100 \mathrm{mV} / \mathrm{s}$. The light measurements were performed under solar light with intensity $1000 \mathrm{~W} / \mathrm{m}^{2}$. The edges of the PEC samples were protected by epoxide during the photo-electrochemical measurements. The measured voltage was calculated versus the reversible hydrogen electrode (RHE).
ASA simulation software [16] was used for simulation of light $I-V$ curves of solar cells. Input parameters for SHJ model used during the simulation were adopted from $[17,18]$. The incident solar spectrum used in ASA for estimation of PEC-PV efficiency was calculated by considering the transmittance of PEC samples and solar spectrum.

\section{Results and discussion}

\subsection{Thin film photo-electrochemical cell}

An important requirement for the hybrid PEC-PV system depicted in Fig. 1 is the transparency and efficiency of the PEC structure. The carbon content was varied during the deposition of both doped and intrinsic a-SiC:H layers by intentional change of $\mathrm{CH}_{4}$ flow to tune both parameters. Figure 2(a) shows the transmittance spectra of samples with varied $\mathrm{CH}_{4}$ flow of 10,5 and $3 \mathrm{sccm}$, labelled as PEC1, PEC2 and PEC3, respectively. All samples exhibit sufficient transparency and can be used with additional solar cells placed behind PEC structures according to the model in Fig. 1. The average transparency decreases with a decrease of the $\mathrm{CH}_{4}$ flow used during fabrication, showing the lowest transparency for PEC3. The measured transmittance spectra allow to construct the Tauc plot and determine the band gap of a-SiC:H layers, Fig. 2(b). The decrease of $\mathrm{CH}_{4}$ flow, in other words expected carbon content in the layer, results in a decrease of the band gap $E_{\mathrm{g}}$ from $2 \mathrm{eV}$ to $1.84 \mathrm{eV}$ and $1.7 \mathrm{eV}$ for PEC1, PEC2 and PEC3, respectively. The decrease of the transmittance with the decrease of the band gap is due to the shifted absorption edge to a higher wavelength and hence increased absorption in the layer.

Linear sweep voltammetry under light with intensity $1000 \mathrm{~W} / \mathrm{m}^{2}$ was carried out to inspect the photoelectrochemical behaviour of the PEC samples. Figure 3 shows $V_{\mathrm{PEC}}(\mathrm{j})$ with photocurrents $0.2,4$, and $50 \mu \mathrm{A} / \mathrm{cm}^{2}$ at $0 \mathrm{~V}$ vs. RHE for samples PEC1, PEC2, and PEC3, respectively. The highest photocurrent is achieved for sample PEC3 which has the lowest carbon content and small- 

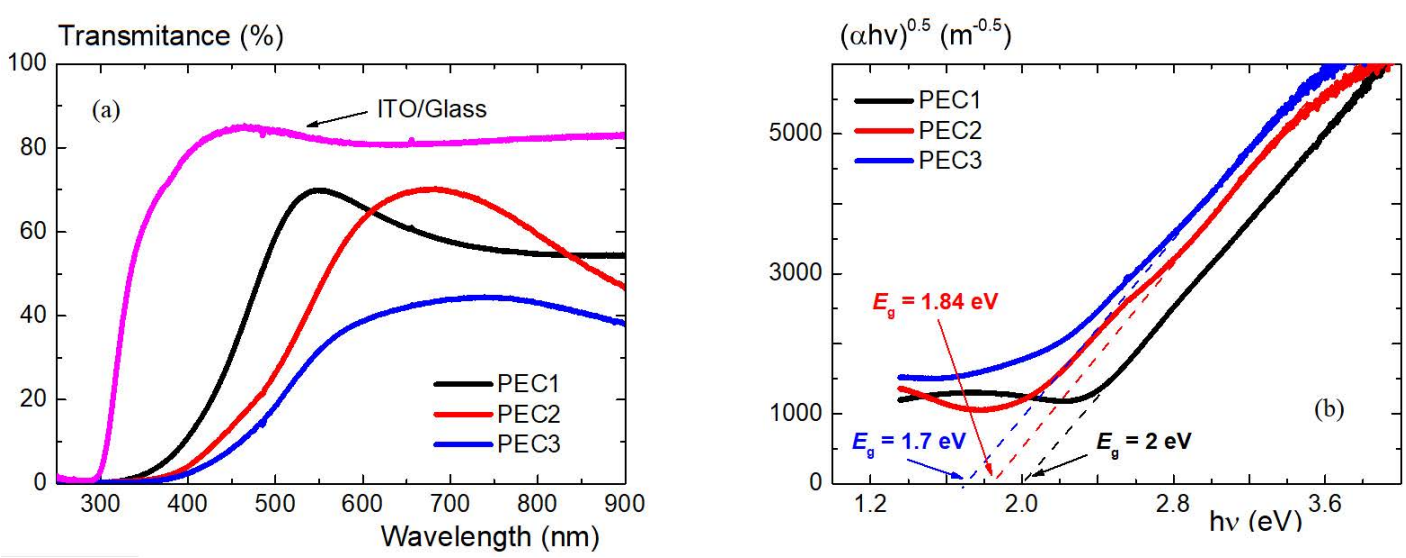

Fig. 2. (a) - Transmittance spectra of PEC samples, (b) - Tauc plot calculated from the transmittance spectra of PEC samples

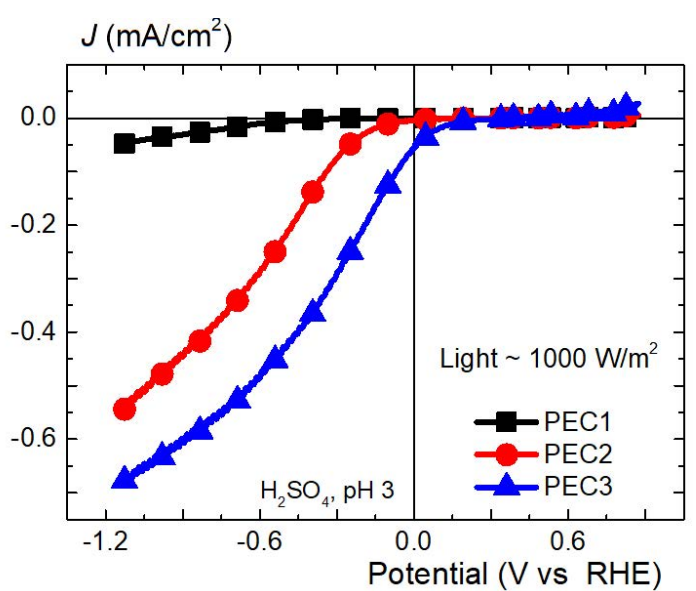

Fig. 3. Linear sweep voltammetry of PEC structures measured in dark and under light $\left(1000 \mathrm{~W} / \mathrm{m}^{2}\right)$

est band gap. This is in accordance with the expected trend with decreased carbon content and hence increased absorption.

\subsection{Hybrid PEC-PV system}

Prepared PEC structures exhibited a low photocurrent at $0 \mathrm{~V}$ vs. RHE and thus a low HER rate. The shift of $V_{\mathrm{PEC}}(\mathrm{j})$ to positive voltages is required to significantly increase the photocurrent. Transparency of the PEC cell allows its usage in conjunction with a solar cell, which can supply the required overpotential. For this purpose an ITO/a-SiC:H/Si silicon heterojunction structure forming simply photovoltaic cell (PV) was prepared. Figure 4 shows current/voltage measurements of the prepared SHJ structure with a $100 \mathrm{~nm}$ thick ITO layer under solar simulator with $1000 \mathrm{~W} / \mathrm{m}^{2}$ and spectrum AM1.5 exhibiting an efficiency of $\eta_{\mathrm{C}}=9.66 \%$. The relatively low $V_{\mathrm{OC}}=0.5$ $\mathrm{V}$ suggests recombination at the a- $\mathrm{SiC}: \mathrm{H}(\mathrm{n}) / \mathrm{c}-\mathrm{Si}(\mathrm{p})$ heterointerface. It is important to emphasize that our sample represents only a simple SHJ structure without an intrinsic passivation layer and back surface recombination fields, which are in state-of-the-art SHJ solar cells responsible for $V_{\mathrm{OC}}$ up to $750 \mathrm{mV}$ [19].

To provide sufficient photovoltage for splitting of water it is necessary to connect the PEC cell with a suf- ficient number of PV cells in series. Three schemes are considered in this study: (i) PEC connected with 3 SHJ, Fig. 1, (ii) PEC connected with 4 SHJ, and (iii) PEC connected with 5 SHJ. The cumulative area of SHJ is equal to the area of PEC in all assumed schemes. To estimate the efficiency of the presented hybrid PEC-PV system, it is important to model $I-V$ characteristic of solar cells connected in series behind the PEC cell. ASA simulation software was used for such a purpose. Figure 5 shows the fit to the measured light $I-V$ curves of SHJ with ITO provided by the simulation model. The obtained fit shows a good match and high validity of the simulation model. In the second step, the spectrum of light behind the PEC3 sample was determined from the transmittance measurements and solar spectrum AM1.5.

This light spectrum, labelled as PEC spectrum, was used in the simulation model to calculate the light $I-V$ characteristics of SHJ behind the PEC. In the last step, $I-V$ characteristics of $1,3,4$ and 5 SHJ structures connected in series were calculated, Fig. 5. Due to the serial connection of the PV cells, the increased number of SHJ provides an increased photovoltage and decreased photocurrent.

The efficiency of water splitting is affected by various factors such as the efficiency of the hydrogen evolution reaction provided by the photocathode, efficiency of the oxygen evolution reaction provided by the anode and by the resistance of the electrolyte. All these parts determine the current voltage characteristic of the hybrid PEC-PV system, $V_{\text {PEC-PV }}(\mathrm{j})$. According to $[20]$, the $V_{\text {PEC-PV }}(\mathrm{j})$ for a standard two-electrode operation is calculated as

$$
V_{P E C-P V}(j)=V_{P V}(j)-\eta_{O E R}(-j)+\eta_{H E R}(j)+j R
$$

where $V_{\mathrm{PV}}(\mathrm{j})$ is the light current-voltage curve of the SHJ, $\eta_{\mathrm{OER}}(\mathrm{j})$ is the OER overpotential at the anode together with the electrode potential for the OER $(1.23$ $\mathrm{V})$, and $\eta_{\mathrm{HER}}(\mathrm{j})$ is the HER overpotential at the PEC photocathode. The overpotential and resistive losses $(\mathrm{R})$ of the electrolyte are considered negligible in this study.

Figure 6(a) shows a graphical representation of $V_{\mathrm{PV}}(\mathrm{j})$, $V_{\text {PEC }}(\mathrm{j}), \eta_{\mathrm{OER}}(\mathrm{j})$ and calculated $V_{\text {PEC-PV }}(\mathrm{j})$ for PEC3 


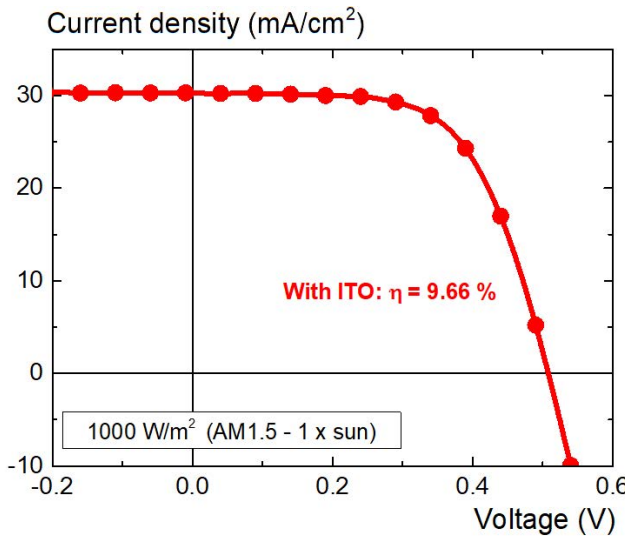

Fig. 4. Light $I-V$ characteristics of ITO/a-SiC:H/Si samples measured under sun simulator with light intensity $1000 \mathrm{~W} / \mathrm{m}^{2}$ and spectrum AM1.5

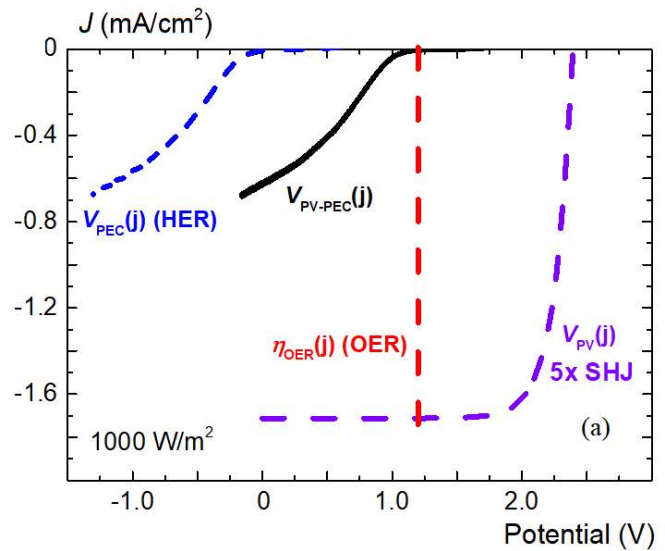

Current density $\left(\mathrm{mA} / \mathrm{cm}^{2}\right)$

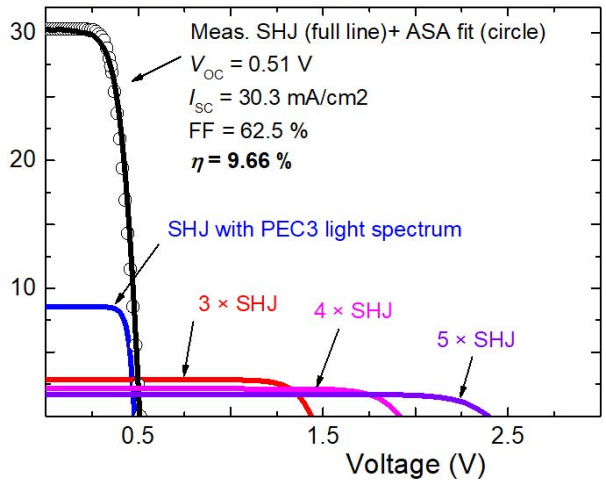

Fig. 5. Measured and modelled $I-V$ characteristic of SHJ and calculated PV part of the hybrid PEC-PV scheme with assumed light spectrum behind PEC3 and 1, 3, 4 and 5 SHJ cells

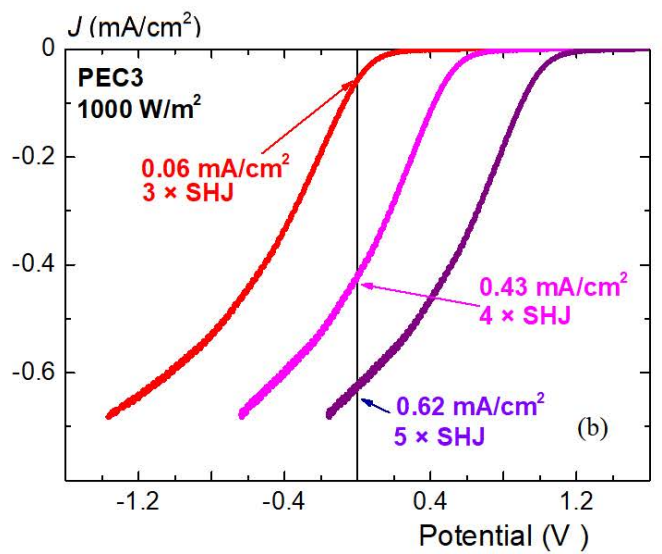

Fig. 6. (a) - Schematic representation for calculation of $V_{\text {PEC-PV }}(\mathrm{j})$, (b) - calculated $V_{\text {PEC-PV }}(\mathrm{j})$ for 3 assumed schemes of PEC connected to 3,4 and 5 SHJ cells

and 5 SHJ. Figure $6(\mathrm{~b})$ shows $V_{\text {PEC-PV }}(\mathrm{j})$ for all assumed schemes of used PEC-PV. The photocurrents of 0.06 , 0.43 , and $0.62 \mathrm{~mA} / \mathrm{cm}^{2}$ at $0 \mathrm{~V}$ vs. RHE are achieved for PEC sample connection to 3, 4 and 5 SHJs, respectively. The solar to hydrogen efficiency $\eta_{\mathrm{STH}}$ can be calculated by the following equation [20]

$$
\eta_{\mathrm{STH}}=\frac{p_{\mathrm{out}}}{p_{\text {in }}}=\frac{\Delta E j_{\mathrm{op}} \eta_{\mathrm{F}}}{w}
$$

where $\Delta E$ - denotes the potential for water decomposition at $25^{\circ} \mathrm{C}$ and is equal to $1.23 \mathrm{~V}, j_{\text {op }}$ - is the operating current and $\eta_{\mathrm{F}}$ - is the Faradaic efficiency for $\mathrm{H}_{2}$ evolution, and $w$ - total integrated power input density. The input power represents the incident intensity of light. The $\eta_{\mathrm{STH}}$ at assumed $100 \%$ Faradaic efficiency is calculated as $0.07,0.53$, and $0.76 \%$ for PEC connected to 3,4 and 5 SHJs, respectively.

The above calculation revealed that maximum $\eta_{\mathrm{STH}}=$ $0.76 \%$ can be achieved for PEC with 5 SHJ connected in series. Figures $6 \mathrm{a}$ and $6 \mathrm{~b}$ show that the main limiting factor for efficiency of PEC with 5 SHJ is the low photocurrent of $50 \mu \mathrm{A} / \mathrm{cm}^{2}$ at $0 \mathrm{~V}$ vs. RHE provided by the PEC cell. This is mainly due to the fact that no catalyst was used to facilitate transport of photo-generated carriers from a-SiC to electrolyte.
Comparing to other research results, the photocurrent of $150 \mu \mathrm{A} / \mathrm{cm}^{2}$ at $0 \mathrm{~V}$ vs. RHE was achieved on an optimized a-SiC structure without catalyst prepared by Digdaya et al [14]. This photocurrent was significantly increased to $2.8 \mathrm{~mA} / \mathrm{cm}^{2}$ at $0 \mathrm{~V}$ vs. RHE after addition of a nickel molybdenum catalyst. The a-SiC based photocathode connected with a-SiC tandem photovoltaic cell in a hybrid $\mathrm{PV} / \mathrm{a}-\mathrm{SiC}$ configuration provided a photocurrent of $1.3 \mathrm{~mA} / \mathrm{cm}^{2}$, which is equal to efficiency $\eta_{\mathrm{STH}}=1.6 \%$ [21]. The a-SiC tandem photovoltaic cell provides a higher photovoltage compared to a single junction PV. Due to this, only one PV was in this case used in the hybrid system. The solar to hydrogen conversion efficiency of $7.9 \%$ was predicted for nc-Si:H/SHJ hybrid tandem cell with a-SiC:H/nc- $\mathrm{SiO}_{\mathrm{x}} / \mathrm{TiO}_{2}$ based photocathode [13]. In this case, a high efficiency was obtained by addition of $\mathrm{Pt}$ catalyst and optical adjustment of PV and PEC parts of the hybrid system. Results obtained from the mentioned groups indicated that the main direction for increasing $\eta_{\mathrm{STH}}$ is the addition of the catalyst on the PEC part of the system. Other important ways for increasing conversion efficiency are i) increase of PEC performance by applying antireflection coatings, ii) further optimization of PEC structure to increase carrier absorption/decrease recombination by modifying the layer thickness and fab- 
rication conditions, and iii) improvement of $\mathrm{PV}$ by application of passivation layers at the heterointerface and preparation of the so-called back surface field to decrease recombination of photo-generated carriers. An important issue for the applicability of the proposed system is the stability of PEC system in harsh environments of the electrolyte, which can be improved by preparation of a protection layer, such as $\mathrm{TiO}_{2}$.

\section{Conclusion}

This paper presents fabrication of a-SiC:H based PEC structures for water splitting. The highest photocurrent of $50 \mu \mathrm{A} / \mathrm{cm}^{2}$ at $0 \mathrm{~V}$ vs. RHE was achieved for a PEC structure with the lowest $\mathrm{CH}_{4}$ flow used during the preparation of the a-SiC:H. This photocurrent was associated to the smallest band gap of a-SiC:H and thus highest absorption of light in the structure. ASA simulation revealed that hybrid a PEC-PV system with SHJ of $9.66 \%$ efficiency can reach $\eta_{\mathrm{STH}} \sim 0.76 \%$ for PEC connected with 5 SHJ solar cells in series. Presented study revealed a good possibility to tune the working point and efficiency of the hybrid PEC-PV system. The main limitation of the efficiency was the low photocurrent of the PEC sample that was prepared without a catalytic layer. A further increase of efficiency can be attained by increasing the performance of both PV and PEC structure.

\section{Acknowledgements}

This work was supported by the Scientific Grant Agency of the Ministry of Education of the Slovak Republic and of the Slovak Academy of Sciences, VEGA $1 / 0651 / 16$, and by the Slovak Research and Development Agency under contracts APVV-17-0169, APVV-15-0152.

\section{REFERENCES}

[1] M. Zeman and Z. Dong, "Heterojunction silicon based solar cells, Physics and technology of amorphous-crystalline heterostructure silicon solar cells", Springer Berlin Heidelberg, pp. 13-43, 2012.

[2] S. De Wolf, A. Descoeudres, ZC. Holman and C. Ballif, "Highefficiency silicon heterojunction solar cells: A review", Green, vol. 2, no. 1, pp. 7-24, 2012.

[3] K. Masuko, M. Shigematsu, T. Hashiguchi, D. Fujishima, M. Kai, N. Yoshimura, T. Yamaguchi, Y. Ichihashi, T. Mishima, N. Matsubara, T. Yamanishi, T. Takahama, M. Taguchi, E. Maruyama and S. Okamoto, "Achievement of more than 25\% conversion efficiency with crystalline silicon heterojunction solar cell", IEEE Journal of Photovoltaics, vol. 4, no. 6, pp. 1433-1435, 2014.

[4] M. Grätzel, "Photoelectrochemical cells", Nature, vol. 414, no. 6861, pp. 338-344, 2001.

[5] N. S. Lewis, "Research opportunities to advance solar energy utilization", Science, vol. 351, no. 6271, pp. 1920, 2016.

[6] J. Bao, "Photoelectrochemical water splitting: A new use for bandgap engineering", Nature nanotechnology, vol. 10, no. 1, pp. 19-20, 2015.
[7] L. M. Peter, "Photoelectrochemical Water Splitting. A Status Assessment", Electroanalysis, vol. 27, no. 4, pp. 864-871, 2015.

[8] J. Hu, F. Zhu, A. Kumath, D. Prasher and N. Gaillard, "Development of monolithically integrated high performance hybrid $\mathrm{PV} / \mathrm{a}-\mathrm{SiC}$ devices for photoelectrochemical water splitting", 2014 IEEE 40th Photovoltaic Specialist Conference (PVSC), pp. 3119-3122, 2014.

[9] G. Wang, H. Wang, Y. Ling, Y. Tang, X. Yang, R. C. Fitzmorris, C. Wang, J. Z. Zhang, and Y. Li, "Hydrogen-Treated TiO2 Nanowire Arrays for Photoelectrochemical Water Splitting", Nano Letters, vol. 11, no. 7, pp. 3026-3033, 2011.

[10] E. L. Miller, R. E. Rocheleau and X. M. Deng, "Design considerations for a hybrid amorphous silicon/photoelectrochemical multijunction cell for hydrogen production", International Journal of Hydrogen Energy, vol. 28, no. 5, pp. 615-623, 2003.

[11] Z. Chen, H. N. Dinh, E. Miller, "Photoelectrochemical Water Splitting", New York: Springer, 2013.

12] L. J. Minggu, W. R. W. Daud and M. B. Kassim, "An overview of photocells and photoreactors for photoelectrochemical water splitting", International Journal of Hydrogen Energy, vol. 35, no. 11 , pp. 5233-5244, 2010.

13] R. Vasudevan, Z. Thanawala, L. Han, T. Buijs, H. Tan, D. Deligiannis, P. Perez-Rodriguez, I. A. Digdaya, W. A. Smith, M. Zeman and A. H. M. Smets, "A thin-film silicon/silicon hetero-junction hybrid solar cell for photoelectrochemical water-reduction applications", Solar Energy Materials and Solar Cells, vol. 150, pp. 82-87, 2016.

14] I. A. Digdaya, L. Han, T. W. F. Buijs, M. Zeman, B. Dam, A. H. M. Smets, and W. A. Smith, "Extracting large photovoltages from a-SiC photocathodes with an amorphous $\mathrm{TiO}_{2}$ front surface field layer for solar hydrogen evolution", Energy \& Environmental Science, vol. 8, no. 5, pp. 1585-1593, 2015.

[15] M. Perný, V. Šály, M. Váry, M. Mikolášek, and J. Huran, "Electrical characterization of a-SiC/c-Si solar cell structures", 38th International Spring Seminar on Electronics Technology (ISSE), IEEE, pp. 16-20, 2015.

16] M. Zeman, J. Van den Heuvel, M. Kroon, J. Willemen, B. Pieters and J. Krč, "Amorphous Semiconductor Analysis (ASA), Users manual, version 5.0", Delft University of Technology, Delft, The Netherlands, 2005.

[17] M. Mikolášek, J. Racko, L. Harmatha, P. Gašpierik and P. Šutta, "Influence of the broken symmetry of defect state distribution at the a-Si: $\mathrm{H} / \mathrm{c}-\mathrm{Si}$ interface on the performance of hetero-junction solar cells", Applied Surface Science, vol. 256, no. 18, pp. 5662-5666, 2010.

[18] M. Mikolášek, J. Racko and L. Harmatha, "Analysis of low temperature output parameters for investigation of silicon heterojunction solar cells", Applied Surface Science, vol. 395, pp. 166-171, 2017.

19] K. Yoshikawa, H. Kawasaki, W. Yoshida, T. Irie, K. Konishi, K. Nakano, T. Uto, D. Adachi, M. Kanematsu, H. Uzu and K. Yamamoto, "Silicon heterojunction solar cell with interdigitated back contacts for a photoconversion efficiency over $26 \%$ ", Nature Energy, vol. 2, pp. 17032, 2017.

[20] F. Urbain, V. Smirnov, J.-P. Becker, U. Rau, J. Ziegler, B. Kaiser, W. Jaegermann, and F. Finger, "Application and modeling of an integrated amorphous silicon tandem based device for solar water splitting", Solar Energy Materials and Solar Cells, vol. 140 , pp. $275-280,2015$.

[21] I. Matulionis, J. Hu, F. Zhu, J. Gallon, N. Gaillard, T. Deutsch, E. Miller, and A. Madan, "Surface modification of a-SiC photoelectrodes for photocurrent enhancement", In Solar Hydrogen and Nanotechnology V, International Society for Optics and Photonics, vol. 7770, pp. 77700Z, 2010.

Received 19 March 2019 